\title{
The Teaching Practice Based on Modern Apprenticeship with Integration of Theory and Practice Teaching Mode
}

\author{
Dayong Huo ${ }^{1, a}$ and Mingxia Ding ${ }^{1, b^{*}}$ \\ ${ }^{1}$ Kashgar University, Kashgar 844006, China \\ ahnnyhdy@163.com, bhnnydmx@163.com \\ * The corresponding author
}

Keywords: Modern apprenticeship; Technology-applied bachelor; Integration of theory and practice teaching mode; Talent training; Distribution technology

\begin{abstract}
Take Distribution Technology's integration of theory and practice teaching mode teaching practice in University of Kashgar for example, in this article, a teaching practice process that uses the talent training mode of modern apprenticeship to carry on the teaching in technology-applied bachelor university engineering's professional course teaching practice is introduced. And it summarizes the practice of curriculum system construction of Distribution Technology's integration of theory and practice teaching mode teaching practice based on modern apprenticeship, including the teaching environment, the quality of teachers, and curriculum development. Moreover, it analyzes the restricting factors in the teaching practice and improve way through teaching reflection as well. It puts forward a viewpoint that the integration of theory and practice teaching mode construction of teaching system based on modern apprenticeship is the only way for technology-applied universities' teaching.
\end{abstract}

\section{基于现代学徒制的理实一体化教学实践 \\ 霍大勇 ${ }^{1, a}$, 丁明霞 ${ }^{1, b^{*}}$ \\ 1. 喀什大学中国 新疆喀什 844006 \\ ahnnyhdy@163.com, bhnnydmx@163.com}

摘要：以喀什大学《供配电技术》理实一体化教学实践为范例, 介绍了在技术应用型本科院 校工科专业的专业课教学实践中运用现代学徒制的人才培养模式进行理实一体化教学的教育 实践过程。总结了基于现代学徒制的《供配电技术》理实一体化教学实践过程中课程体系构 建的经验, 包含: 授课环境、教师素质、课程开发。通过教学反思, 分析了教学实践中的制约 因素和改善途径。提出了基于现代学徒制的理实一体化教学体系构建是工科技术应用型院校 教学的必由之路的观点。

关键词：现代学徒制；技术应用型本科; 理实一体化; 人才培养; 供配电技术

\section{1. 引言}

目前，中国高等教育进入 “优化结构、办出特色” 阶段。中华人民共和国《国家中长期教育 改革和发展 (2010-2020) 规划纲要》指出, “高等教育要适应国家和区域经济社会发展需要, 建立动态调整机制, 不断优化高等教育结构。优化学科专业、类型、层次结构, 促进多学科 交叉和融合。重点扩大应用型、复合型、技能型人才培养规模。”[1]技术应用型本科院校是 中华人民共和国教育部基于培养高层次技术技能型人才的需求对本科办学方向的一种调整类 型。《国务院关于加快发展现代职业教育的决定》要求 “引导普通本科高等学校转型发展。 采取试点推动、示范引领等方式, 引导一批普通本科高等学校向应用技术类型高等学校转型, 
重点举办本科职业教育。”[2]喀什大学是新疆维吾尔族自治区第一批试点转型的技术技能应 用型综合性大学, 在转型实践中, 我们结合本地区的区域工业发展特点, 在电气工程及其自 动化专业的人才培养方案中贯彻实施了应用技术型大学的发展理念。在专业课教学中, 结合 实际, 创造性地运用了现代学徒制的教育模式, 进行了理实一体化教学改革。在《供配电技 术》教学实践中取得了较好的效果。报告如下:

\section{2. 教学思路的产生背景}

2.1. 技术应用型本科高校的建设

文献一和文献二均指出大力培养应用型、复合型、技能型、创新型人才。这是高校办学方向 性的指引, 为本科院校的发展开阔了视野, 指明了方向, 提供了改革发展的动力。这一思路 引导了新时期中国本科院校实现在发展方向上的分类。技术应用型本科高校的发展方向就是 培养高水平的一线技能型人才。其培养人才的目标更加倾向于动手能力、实践能力和创新能 力。显著不同于理论研究、高端科技的研发方向。技术应用型高校的建设也就要更加注重于 卓越工程师人才养成所需求的双师型导师、真实性的产研工作环境。在教师和实训建设方面 对面向应用型转型的高校是极大的挑战。

2.2. 现代学徒制人才培养模式

现代学徒制是将学校形态的职业教育与自然形态的学徒制相结合的一种教育形式, 起源于联 邦德国的职业培训，上个世纪 80 年代开始在发达国家广泛推行。[3] 2015 年，中华人民共 和国教育部门出台《关于开展现代学徒制试点工作的意见》, 提出现代学徒制试点工作。现代 学徒制的培养目标是完成 “职业的典型工作任务” 所需的综合职业能力, 并在真实的工作情 境中获得 “工作过程知识”。与传统学徒制操作技能训练和学校教育传授学术知识不同。[4] 现 代学徒制的要素是双师型的导师和真实的工作环境。现代学徒制倡导在企业进行现场教学。

2.3. 理实一体化的授课方式

理实一体化教学方式起源于德国的 “双元制” 教学, 适用于培养技能应用型人才。这种模式 集教、学、做于一体, 理论与实践相互融合, 以培养学生综合职业能力为目的, 是目前职教 界公认的培养技术技能人才的专业课堂教学最佳模式之一。[5-8] 理实一体化的授课方式第 一需要双师型的教师, 具备理论授课和实践授课的双重能力, 其中实践授课包含设计、设备 维修和运行能力。第二需要真实的现场生产环境。理实一体化方式倾向在学校实训室授课。

2.4. 现代学徒制模式与理实一体化教学方法的契合

将教学和产业过程紧密结合, 以企业真实产品和现实工作任务为教学载体, 采用企业管理模 式, 在校内一体化教室、专业实训室或企业生产车间进行, 实现教、学、练、做一体化教学, 学生在生产实际中通过自身的行动, 不断学习知识、提高操作技能、解决实际工作问题, 提 高职业能力素养。双师型的导师和真实的工作环境是 “现代学徒制模式” 与 “理实一体化教 学方法” 的契合点。不同之处在于两者的授课地点倾向。前者在工厂, 后者在校内基地。两 者对于师资的要求、对于教学环境的要求事实上是一致的。

2.5. 现代学徒模式、理实一体化教法符合技术应用型教育的目标

现代学徒制 “学习者只有亲自完成一系列能够为职业发展提供帮助的典型工作任务, 才能发 展职业能力” [4]的理念; 理实一体化教学方式以 “培养学生综合职业能力为目的” ; 两者结 合符合 “培养应用型、复合型、技能型、创新型人才” 技术应用型教育的目标。喀什大学的 定位是技术应用型大学, 我们在电气工程及其自动化专业开展了基于现代学徒制的理实一体 化教学实践, 《供配电技术》课程是其中先期进行的教学实践之一。 


\section{3. 基于现代学徒制的《供配电技术》理实一体化教学实践}

\section{1. 课程体系构建}

将《供配电技术》课程划分为 3 类 54 个知识点。

课程中的三种教学类别分别为设计计算类、运行维护类和生产管理类。其中设计计算类按照 生产设计部门, 如工程预算员、供配电设计技术员岗位的能力要求进行教学设计; 运行维护 类按照维修和施工技术员的岗位要求设计教学; 生产管理类按照工程监理和电力运行管理岗 位设计教学。总学时为课内 72 小时。每个知识点按实际岗位的工作步骤进行分类达标考核。

\section{2. 授课模式}

设计计算类知识点在设计室进行教学。工作程序为: 设计任务的分配、团队的组成、设计指 标的拟定、设计资料的检索、设计相关知识的学习 (理论授课)、设计的实施。运行维护类知 识点在专业实训室进行教学。工作程序为: 器件的基本原理与构成 (理论授课)、器件的拆装、 器件的维护、综合故障的查找与排除。期间穿插安全生产知识, 企业文化教育。生产管理类 知识点在设计室和实训室分别进行。工作程序为: 安全生产的督查、生产管理中的角色模拟。 如材料员、工具员、安全员、监理员、工程质量检验员、验收员、班组长、调度员、车间主 任等。进行撰写通知、报告、工作票、技术总结、合同文件等训练。

\section{3. 授课环境}

基于现代学徒制的理实一体化《供配电技术》教学环境完全在喀什大学校园内进行。不同于 现代学徒制思想中的校企合作、以企业为主的思路。我们在理实一体化设计室、实训室建设 上按照真实的生产现场进行布置, 由电力生产运行的技术人员参与构建教学环境, 达到了真 实环境下不能实现的效果。表现在三个方面: 一是每个知识点授课能够达到全体学生的统一, 而实际工作岗位因场地局限性不能满足班级整体建制的学生同步学习的需求; 二是授课可以 按照计划有序进行, 而实际工作场所因为生产进程的局限不可能随时都有生产任务供学生参 与; 三是知识点教授的可重复性，这也是实际工作场所不能满足的。

3. 4. 教师

本教学改革的实现需要教师承担的角色包含：工矿企业设计部门的管理者、现场技术员、工 艺员、设计员、维修员，同时具备授课能力。这就不仅仅需要工程师+教师的双师型教师，还 要求该任课教师具有生产现场的管理经验和实际设计的经验。也就是说本课程人才培养目标 所涵盖的岗位该任课教师都应当具有实际的工作经历。我们选择了这样的教师担任该课程的 授课。

\section{5. 教学效果}

通过本课程的学习, 在期末实践考核中及格率 $97.14 \%$, 比同班级同类课程的成绩高 15 个百 分点。学生到周边电力运行企业进行实习受到欢迎, 并有电力运行企业因学生良好的供配电 专业知识和实践能力, 与实施课改班级的二年级学生达成就业意向。

\section{4. 教学反思}

4.1. 理实一体化教学方式的发展

4.1. 1 制约因素

通过本课改实践, 我们意识到, 目前制约理实一体化教学方式在技术应用型高校发展的首要 因素在于教师。要求所有的教师都具备本课改的素质显然是不可能的。第二个关键因素是完 善的实训实践教室, 目前高校均不完全具备本课改所需求的设施条件。

\section{1.2 改善途径}

培养符合理实一体化教学的教师, 对于高校而言, 目前要做的是一方面聘请企业能手任教实 践环节, 另一方面加大教师到企业参与社会实践的力度。教师队伍的双师型结构通常要求教 师既要具备教师职业能力, 又要具备工程师职业能力。高校中的教师构成是多样的, 有学术 
型、技能型、应用型, 技术型。这就需要建立教学团队, 要充分发挥团队的优势, 形成合力 完成理实一体化教学所需要的环节。[9]设备方面, 需要对向应用型本科转型的高校加大投入。 建设真实型的设计室、实训生产车间。

4.2. 现代学徒制教学模式的发展

4.2.1 制约因素

现代学徒制的实施是一个复杂的工程, 其发展的基础是产教融合及其有效实现形式, 总体上, 中国现代学徒制的发展困难重重, 普遍的现象是 “学校热, 企业冷”。[3]因此, 需要积极探 索如何通过政府、行业、企业、学校和学生等多方努力共同实施现代学徒制的有效方法。

4.2.2 改善途径

本课改采用的模拟真实环境是一个有效的方法。目前 “厂中校” 距离应用型人才培养的需求 尚有距离; 而 “校中厂” 的实施更符合现实条件。

4. 3. 技术应用型工科院校的专业课教学

应用型工科高校要走合作教育之路, 打破学校的边界、专业的边界、课程的边界、课堂的边 界、教师隶属的边界, 依据政府、高校、企业、科研机构及社会其他子系统各方利益需求, 形成资源共建、全程参与、互利共赢的新型培养模式合作教育机制是这类学校发展的关键之 路。[9-10]技术应用型工科专业课的教学尘须以现场经验为支撑的教师为主力军, 辅之以真 实的工作环境。这就要求广泛的产、学、研结合为基础、校、企、政府三方合作为纽带。基 于现代学徒制的理实一体化教学体系构建是工科技术应用型院校教学的必由之路。

\section{参考文献}

[1] 国家中长期教育改革和发展规划纲要[M]. 国务院文件,2010.07.

[2] 国务院关于加快发展现代职业教育的决定[M]. 国务院文件,2014.05.

[3] 杨延. 应用现代学徒制培养高端制造业人才. 中国教育报[N].2014.12.17.

[4] 着力构建现代学徒制培养体系[M]. 教育部, 2014.09.

[5] 张艳霞, 张景杰. 理实一体化教学模式在电机与施动裸程中的实施众推广 [J]. 郑州航空工 业管理学院学报(社会科学版), 2016, 35(2):201-204.

[6] 王卫卫. 理实一体化教学模式在《电机与拖动》课程中的应用[J].武汉船舶职业技术学院 学报, 2014,13(6):156-158.

[7] 许丽梅.理实一体化教学实践与研究[J]. 汽车维修与保养 2013,(11);96-99.

[8] 刘勇.理实一体化教学质量影响要素研究[J]. 职教通讯, 2013,(24):31-35.

[9] 陈小虎,杨祥. 新型应用型本科院校发展的 14 个基本问题 [J]. 中国大学教学, 2013,35(1):17-22.

[10]吴中江，黄成亮. 应用型人才内涵及应用型本科人才培养 [J]. 高等工程教育研究,2014, 32(2):66-70.

\section{Acknowledgement}

This research was financially supported by the 2015 Teaching Reform Research Planning Project of Kashgar University (KJAZ1503). 


\section{References}

[1] National medium and long-term plan for education reform and development [M], The State Council of the People's Republic of China, Beijing, 2010.05.

[2] The state council about accelerate the development of modern vocational education decision [M], The State Council of the People's Republic of China, Beijing, 2014.07.

[3] Y. Yang: Modern apprenticeship training high-end manufacturing industry in urgent need of talents [N], China Education Daily, Beijing, 2014.12.17.

[4] Strive to build modern apprenticeship training system [M], The Ministry of Education of the People's Republic of China, Beijing 2014.09.

[5] Y.X Zhang, J.J Zhang: Implementation and Promotion on Integration of theory and practice teaching mode in Motor and Drive Course[J], Journal of Zhengzhou University of Aeronautics(Social Science Edition),Vol.35(2016)No.2, pp.201-204.

[6] W.W Wang: On Motor and Drive Course Teaching through Integration of theory and Practice[J], Journal of Wuhan Institute of Shipbuilding Technology, Vol.13 (2014) No.6, pp.156-158.

[7] L.M Xu:Real integration teaching practice and research [J], Motor China, Vol.19 (2013) No.11, pp. 96-99.

[8] Y. Liu: Real integration, main factors affecting the quality of teaching research[J], Communication of Vocational Education, Vol.29 (2013) No.24, pp.31-35.

[9] X.H Chen, X Yang: Fourteen basic questions in the development of applied undergraduate colleges and universities [J], China University Teaching, Vol.35 (2013) No.1, pp.281-304.

[10]Z.J Wu, C.L Huang: The Concept and Cultivation of Applied Talents [J], Research in Higher Education of Engineering, Vol.32 (2014) No.2, pp.66-70.

作者简介: 霍大勇 $(1967-)$, 男, 河南南阳人, 教授, 主要从事设备管理与维护、教育技术 研究, E-mail: hnnyhdy@163. com 